\title{
新型手性质子酸应用于吲哚催化不对称还原
}

\author{
朱 庆 ${ }^{a, b}$ 刘超*,a \\ ( ${ }^{a}$ 中国科学院兰州化学物理研究所 羰基合成与选择氧化国家重点实验室 兰州 730000) \\ $\left(^{b}\right.$ 中国科学院大学 北京 100049)
}

\section{New Chiral Brønsted Acid for Asymmetric Reduction of Indoles}

\author{
Zhu, Qing ${ }^{a, b}$ Liu, Chao ${ }^{*, a}$ \\ ( ${ }^{a}$ State Key Laboratory for Oxo Synthesis and Selective Oxidation, Lanzhou Institute of Chemical Physics, \\ Chinese Academy of Sciences, Lanzhou 730000) \\ ( ${ }^{b}$ University of Chinese Academy of Sciences, Beijing 100049)
}

手性质子酸在不对称催化中有着重要的应用. 作为 一种弱的质子酸, 水分子可以与路易斯酸性的嗍化合物 结合产生强的质子酸 ${ }^{[1]}$, 这类结合型的混合酸(designer acids)相比较其前体单体酸(individual acids)而言, 往往 具有更高的反应活性, 更好的选择性以及更丰富的反应 类型 ${ }^{[2-3]}$. 另一方面, 手性磷酸与硼类化合物结合产生的 手性磷酸硼络合物(CPAB), 能够有效实现酮和亚胺的 不对称还原反应 ${ }^{[4-5]}$. 然而, 具有一定路易斯酸碱对特性 的手性磷酸嗍络合物 (CPAB) 与水分子结合产生手性质 子酸的研究却没有报道.

最近, 福州大学化学学院宋秋玲课题组联合南方科 技大学化学系余沛源课题组将实验与理论计算相结合, 发展了由水分子与 CPAB 结合产生手性质子酸的研究策 略, 并成功将其应用于 $\mathrm{C} 2$-芳基取代的 $\mathrm{N}-\mathrm{H}$ 吲哚的催
化不对称氢化还原 ${ }^{[6]}$. 该类化合物的不对称氢化一直是 具有挑战的课题 ${ }^{[7-8]}$.

首先，作者利用密度泛函理论计算(DFT)表明，磷 酸和邻苯二酚硼烷(HBcat)反应生成磷酸硼络合物是放 热过程, 磷酸硼络合物和水作用产生质子酸是热力学有 利的过程，该结果也通过核磁 ${ }^{1} \mathrm{H} N \mathrm{NM}$ 和 ${ }^{31} \mathrm{P}$ NMR 谱进 一步确. DFT 计算也表明, 得到的质子酸的酸性强于 $\mathrm{TsOH}$ (Scheme 1). 随后，作者利用双苯基酯类手性磷酸 作为催化剂前体, HBcat 作为还原剂的同时与手性磷酸 在反应体系中现场生成手性磷酸硼, 通过添加水产生手 性质子酸. 控制实验表明, 不加水反应几乎不能进行, 反应以甲苯作溶剂, 在低温 $-50{ }^{\circ} \mathrm{C}$ 条件下, 2 -芳基吲哚 的不对称氢化能够顺利进行, 并以高产率和高对映选择 性得到相应的手性 2-芳基二氢吲哚类化合物 ${ }^{[6]}$.

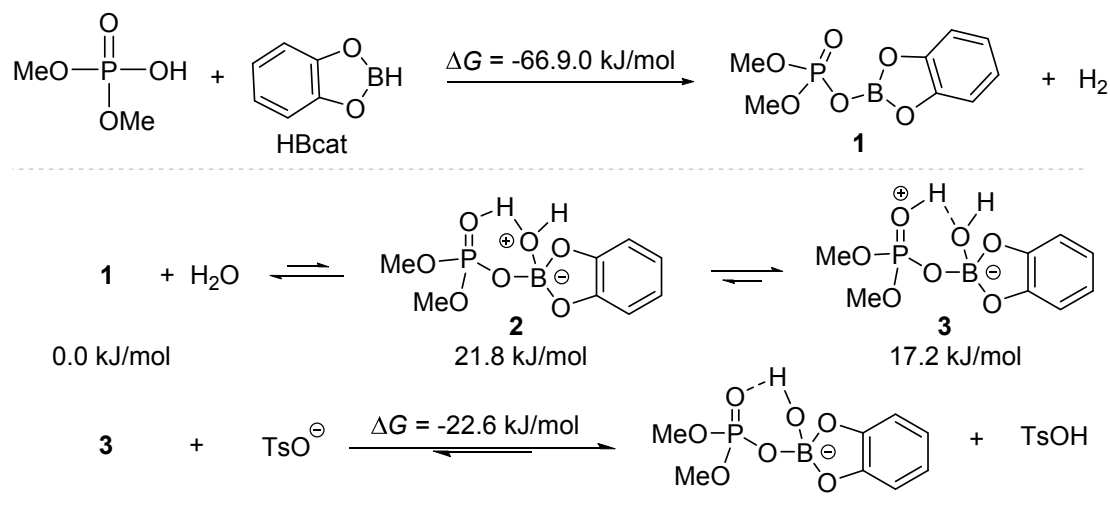

图式 1 磷酸硼络合物与水分子结合产生质子酸

Scheme 1 Brønsted acid derived from a phosphoric acid boron complex and water

* Corresponding author. E-mail: chaoliu@licp.cas.cn. Published online May 23, 2020. 
确定最优条件后, 作者对于吲哚芳环以及 2-芳基上 的取代基分别进行了考察, 各种官能团如 $\mathrm{OMe}, \mathrm{CF}_{3}$, $\mathrm{CN}, \mathrm{NO}_{2}$, Bpin 等都能很好的兼容该反应条件, 并以较 高的对映选择性得到不对称氢化产物(Scheme 2). 有趣 的是, 7-Me 取代的吲哚(6f)在反应结束后给出了相反构 型的产物, 且具有 $64 \% \mathrm{ee}$, 这一结果表明在吲哚的 $\mathrm{NH}$ 附近的空间位阻对反应存在一定的影响. 而一些特殊结 构的吲哚如具有烯烃、炔烃结构的吲哚也能给出相应的 不对称氢化产物，而不会发生烯烃、炔烃氢化的副反应， 表明该反应具有优秀的化学选择性. 作者也对大位阻 2烷基取代的吲哚进行了不对称氢化反应，当使用 CPA2 作为催化剂时, 反应能以中等的产率以及较高的对映选 择性得到目标产物(6k).

为了进一步拓展该方法的实用性, 首先, 作者将模 板反应放大至克级. 将得到的 $(S)$-2-苯基二氢吲哚 $\mathbf{6 a}$ 与
甲烷三羧酸三乙酯一步转化为化合物 7 , 化合物 7 是 HIF (hypoxia-inducible factor，缺氧诱导因子)脯氨酰羟 化酶抑制剂的一种对映异构体的前体. 同时, (S)-2-苯基 二氢吲哚 $6 \mathrm{a}$ 与化合物 8 缩合得到化合物 9 是一种丝氨 酸/苏氨酸激酶 $(\mathrm{AKT}$, 也称为 $\mathrm{PKB}$, protein kinase B 蛋白 激酶 $\mathrm{B}$ )磷酸化抑制剂. 最后，可以通过 $(S)-2$-苯基二氢 吲哚 $6 \mathrm{a}$ 与苯乙腈的苯甲酰化以及随后的缩合得到手性 配体 11 (Scheme 3).

为了更好的解释机理，作者使用 $\mathrm{D}_{2} \mathrm{O}$ 代替 $\mathrm{H}_{2} \mathrm{O}$ 参与 反应(Scheme 4a), 发现 C-3 位出现两个氛, 这一实验现 象表明, 反应历程中会经历一个可逆的 C-3 质子化过程 并形成亚胺中间体. 使用甲基保护的 2-芳基吲哚 12 参 与反应得到消旋的产物, 这一结果表明吲哚上 $\mathrm{NH}$ 的存 在对对映选择性控制至关重要, 可能是与控制对映选择 性的关键中间体有氢键相互作用(Scheme 4b). DFT 计算
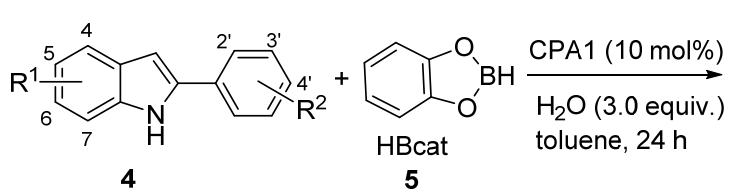

Selected examples

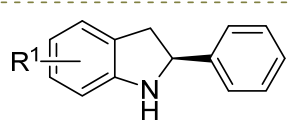

6a, $\mathrm{R}^{1}=5-\mathrm{H}, 88 \%$ yield, $91 \%$ ee 6b, $\mathrm{R}^{1}=5-\mathrm{CF}_{3}, 62 \%$ yield, $92 \%$ ee $6 c, R^{1}=5-B p i n, 74 \%$ yield, $96 \%$ ee 6d, $\mathrm{R}^{1}=4-\mathrm{Cl}, 83 \%$ yield, $91 \%$ ee $6 e, R^{1}=6-F, 78 \%$ yield, $92 \%$ ee 6f, $R^{1}=7-\mathrm{Me}, 97 \%$ yield, $64 \%$ ee
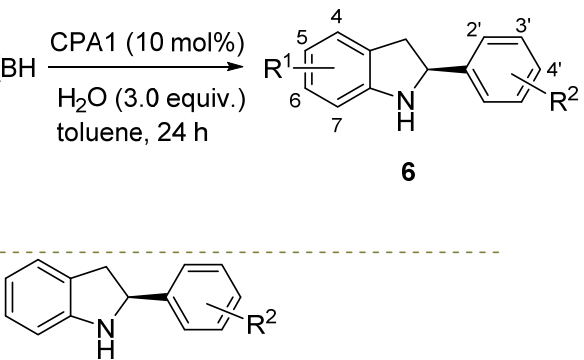

$6 \mathrm{~g}, \mathrm{R}^{1}=3^{\prime}-\mathrm{F}, 90 \%$ yield, $84 \%$ ee $6 \mathrm{~h}, \mathrm{R}^{1}=2^{\prime}-\mathrm{Me}, 82 \%$ yield, $83 \%$ ee $6 \mathbf{i}, \mathrm{R}^{1}=4^{\prime}-\mathrm{OMe}, 87 \%$ yield, $90 \%$ ee $6 j, R^{1}=2 '-F, 4^{\prime}-O M e, 95 \%$ yield, $86 \%$ ee<smiles>O=P(O)(Oc1ccccc1)Oc1c(Br)cc2c(c1-c1c(Br)cc3c(c1Br)CCCC3)CCCC2</smiles>
$\mathrm{CPA} 1: \mathrm{Ar}=2,4,6-\mathrm{Me}_{3} \mathrm{C}_{6} \mathrm{H}_{2}$ CPA2: $\mathrm{Ar}=2,4,6-\mathrm{Cy}_{3} \mathrm{C}_{6} \mathrm{H}_{2}$<smiles>CCC(C)(C)[C@@H]1Cc2cc([N+](=O)[O-])ccc2N1</smiles>

$6 \mathbf{k}^{a}, 57 \%$ yield, $89 \%$ ee ${ }^{a}$ CPA2 was used instead of CPA1

图式 2 底物拓展

Scheme 2 Substrate scope

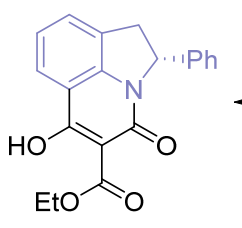

7, $79 \%$ yield, $94 \%$ ee

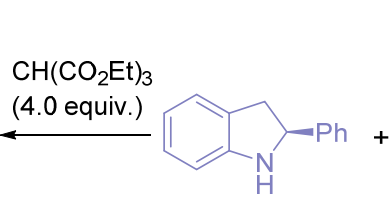

6a, $91 \%$ ee

$1.1 \mathrm{~g}(86 \%$ yield $)$<smiles>CC(C)(C)Cc1nc(N2CCOCC2)cc(=O)[nH]1</smiles>

8<smiles>O=C(Cc1nc(N2CCOCC2)cc(=O)[nH]1)N1c2ccccc2C[C@H]1c1ccccc1</smiles>

9, $65 \%$ yield, $93 \%$ ee

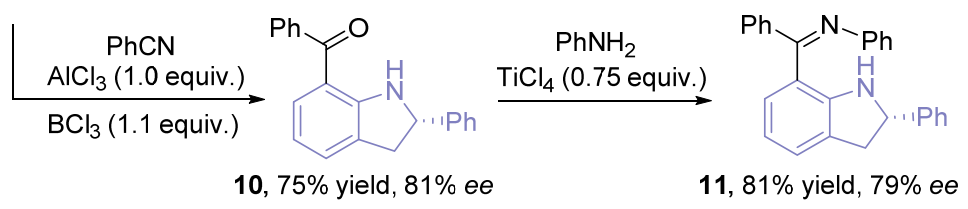

图式 3 合成应用

Scheme 3 Synthetic applications 


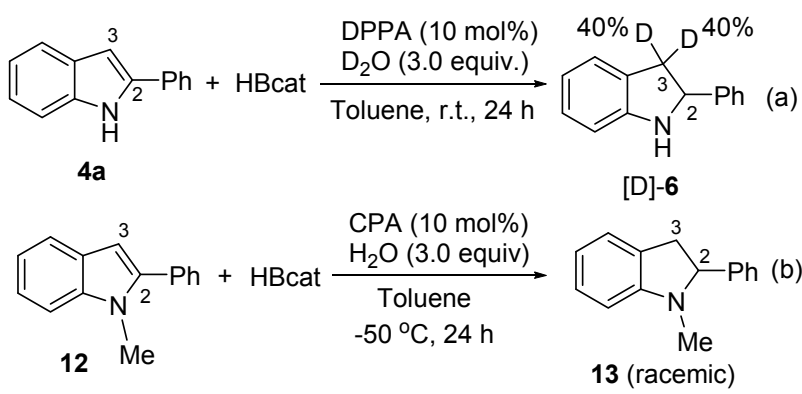<smiles>O=P1(OCN2c3ccccc3CC2c2ccccc2)OCCO1</smiles><smiles>O=P1(O[B-]([O-])(O)O)OCC[NH+]1COP1([O-])=C(c2ccccc2)Cc2ccccc21</smiles>

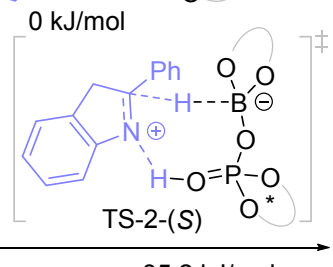

$35.2 \mathrm{~kJ} / \mathrm{mol}$

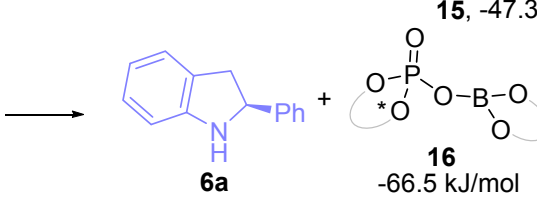

图式 4 机理研究

Scheme 4 Mechanistic studies
表明反应初期形成 CPAB, 在引入 2-苯基吲哚后会在其 C3 位形成亚胺中间体，随后发生分子间的硼交换以及 负氢转移得到产物并释放 CPAB (Scheme 4).

总之, 宋秋玲课题组联合余沛源课题组将实验与理 论计算相结合，深入研究了手性磷酸硼络合物和水分子 作用产生手性质子酸并将其应用于吲哚催化不对称氢 化的过程，解决了具有挑战的 2-芳基吲哚的催化不对称 氢化合成一系列手性 2-芳基二氢吲哚类化合物，反应具 有良好的官能团兼容性，并将之用于药物以及配体的合 成.

\section{References}

[1] Dryzhakov, M.; Moran, J. ACS Catal. 2016, 6, 3670.

[2] Parmar, D.; Sugiono, E.; Raja, S.; Rueping, M., Chem. Rev. 2014, 114, 9047.

[3] Wang, Y.-B.; Tan, B., Acc. Chem. Res. 2018, 51, 534.

[4] Zhang, Z.; Jain, P.; Antilla, J. C., Angew. Chem. Int. Ed. 2011, 50, 10961.

[5] Zhou, Q.; Meng, W.; Yang, J.; Du, H., Angew. Chem. Int. Ed. 2018, 57,12111

[6] Yang, K.; Lou, Y.; Wang, C.; Qi, L.-W.; Fang, T.; Zhang, F.; Xu, H.; Zhou, L.; Li, W.; Zhang, G.; Yu, P.; Song, Q., Angew. Chem. Int. Ed. 2020, 59, 3294.

[7] Zhou, Y.-G., Acc. Chem. Res. 2007, 40, 1357.

[8] Wen, J.; Fan, X.; Tan, R.; Chien, H.-C.; Zhou, Q.; Chung, L. W.; Zhang, X., Org. Lett. 2018, 20, 2143.

(Sun, H.) 